Old Dominion University ODU Digital Commons

Electrical \& Computer Engineering Faculty

Publications

Electrical \& Computer Engineering

2005

\title{
Optimization of Ultraviolet Emission and Chemical Species Generation from a Pulsed Dielectric Barrier Discharge at Atmospheric Pressure
}

Xinpei Lu

Mounir Laroussi

Old Dominion University, mlarouss@odu.edu

Follow this and additional works at: https://digitalcommons.odu.edu/ece_fac_pubs

Part of the Electrical and Computer Engineering Commons, Engineering Physics Commons, and the Plasma and Beam Physics Commons

\section{Repository Citation}

$\mathrm{Lu}$, Xinpei and Laroussi, Mounir, "Optimization of Ultraviolet Emission and Chemical Species Generation from a Pulsed Dielectric Barrier Discharge at Atmospheric Pressure" (2005). Electrical \& Computer Engineering Faculty Publications. 12.

https://digitalcommons.odu.edu/ece_fac_pubs/12

\section{Original Publication Citation}

$\mathrm{Lu}, \mathrm{X}$., \& Laroussi, M. (2005). Optimization of ultraviolet emission and chemical species generation from a pulsed dielectric barrier discharge at atmospheric pressure. Journal of Applied Physics, 98(023301), 1-5. doi: 10.1063/1.1980530

This Article is brought to you for free and open access by the Electrical \& Computer Engineering at ODU Digital Commons. It has been accepted for inclusion in Electrical \& Computer Engineering Faculty Publications by an authorized administrator of ODU Digital Commons. For more information, please contact digitalcommons@odu.edu. 


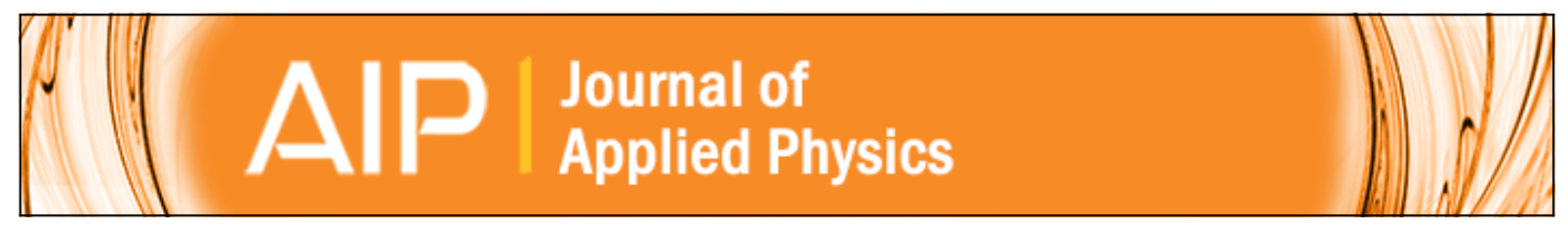

\section{Optimization of ultraviolet emission and chemical species generation from a pulsed dielectric barrier discharge at atmospheric pressure}

Xinpei Lu and Mounir Laroussi

Citation: Journal of Applied Physics 98, 023301 (2005); doi: 10.1063/1.1980530

View online: http://dx.doi.org/10.1063/1.1980530

View Table of Contents: http://scitation.aip.org/content/aip/journal/jap/98/2?ver=pdfcov

Published by the AIP Publishing

\section{Articles you may be interested in}

Methane activation using noble gases in a dielectric barrier discharge reactor

Phys. Plasmas 20, 083509 (2013); 10.1063/1.4818795

Development of a stable dielectric-barrier discharge enhanced laminar plasma jet generated at atmospheric pressure

Appl. Phys. Lett. 100, 253505 (2012); 10.1063/1.4729818

Development of a real time monitor and multivariate method for long term diagnostics of atmospheric pressure dielectric barrier discharges: Application to $\mathrm{He}, \mathrm{He} / \mathrm{N} 2$, and $\mathrm{He} / \mathrm{O} 2$ discharges

Rev. Sci. Instrum. 82, 083501 (2011); 10.1063/1.3624743

Characterization of the behavior of chemically reactive species in a nonequilibrium inductively coupled argonhydrogen thermal plasma under pulse-modulated operation

J. Appl. Phys. 100, 103303 (2006); 10.1063/1.2364623

Electron density and temperature measurement method by using emission spectroscopy in atmospheric pressure nonequilibrium nitrogen plasmas

Phys. Plasmas 13, 093501 (2006); 10.1063/1.2338282

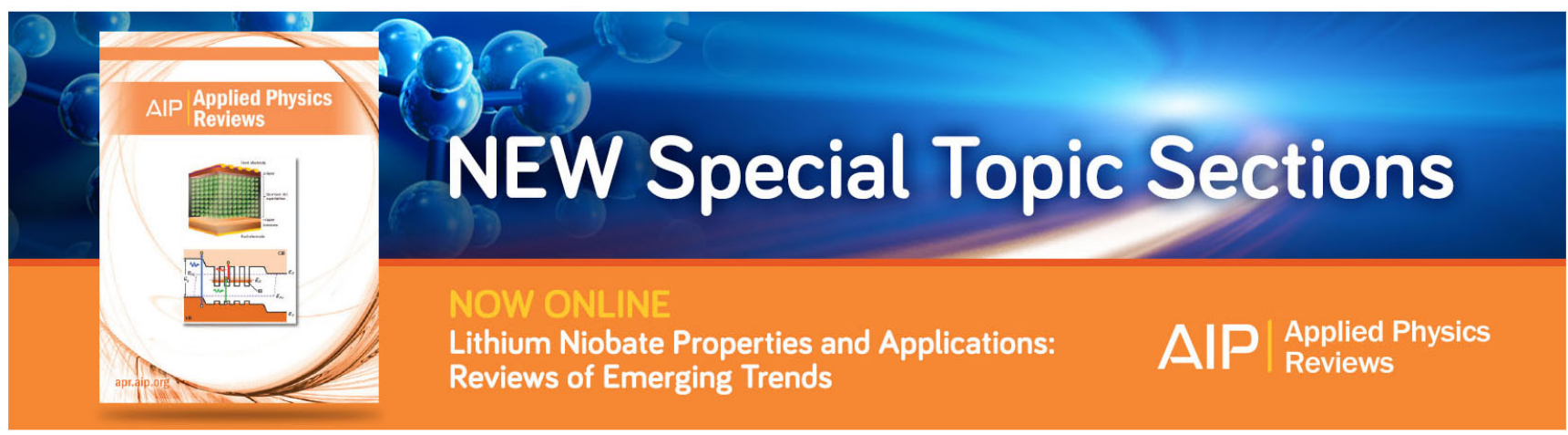




\title{
Optimization of ultraviolet emission and chemical species generation from a pulsed dielectric barrier discharge at atmospheric pressure
}

\author{
Xinpei Lu and Mounir Laroussi ${ }^{\text {a) }}$ \\ Old Dominion University, Norfolk, Virginia 23529
}

(Received 22 December 2004; accepted 1 June 2005; published online 18 July 2005)

\begin{abstract}
One of the attractive features of nonthermal atmospheric pressure plasmas is the ability to achieve enhanced gas phase chemistry without the need for elevated gas temperatures. This attractive characteristic recently led to their extensive use in applications that require low temperatures, such as material processing and biomedical applications. The agents responsible for the efficient plasma reactivity are the ultraviolet (UV) photons and the chemically reactive species. In this paper, in order to optimize the UV radiation and reactive species generation efficiency, the plasma was generated by a dielectric barrier discharge driven by unipolar submicrosecond square pulses. To keep the discharge diffuse and to maintain low operating temperatures, helium (He) was used as a carrier gas. Mixed with helium, varying amounts of nitrogen $\left(\mathrm{N}_{2}\right)$ with the presence of trace amounts of air were used. The gas temperature was determined to be about $350 \mathrm{~K}$ at a $1-\mathrm{kHz}$ pulse frequency for all cases and only slightly increased with frequency. The UV emission power density, $P_{\mathrm{UV}}$, reached its highest level when $5 \%$ to $10 \%$ of $\mathrm{N}_{2}$ is mixed to a balance of He. A maximum $P_{\mathrm{UV}}$ of about $0.8 \mathrm{~mW} / \mathrm{cm}^{2}$ at $10-\mathrm{kHz}$ pulse frequency for a $\mathrm{He}(90 \%)+\mathrm{N}_{2}(10 \%)$ mixture was measured. This was more than four times higher than that when $\mathrm{He}$ or $\mathrm{N}_{2}$ alone was used. Furthermore, the emission spectra showed that most of the UV was emitted by excited NO radicals, where the oxygen atoms came from residual trace amounts of air. In addition to $\mathrm{NO}, \mathrm{NO}_{2}$, and excited $\mathrm{N}_{2}, \mathrm{~N}_{2}^{+}, \mathrm{OH}$, and $\mathrm{He}$ were also present in the plasma. (C) 2005 American Institute of Physics. [DOI: 10.1063/1.1980530]
\end{abstract}

\section{INTRODUCTION}

Atmospheric pressure nonthermal plasmas have recently received increased attention because of several emerging applications such as surface modification of polymers, biological and chemical decontamination of media, aerodynamic drag reduction, and shock-wave mitigation. ${ }^{1-6}$

The main agents that are responsible for the efficient plasma reactivity are ultraviolet (UV) photons and/or the reactive neutral species, and possibly the charged particles. ${ }^{7,8}$ To enhance the ionization and excitation processes, fastrising voltage pulses (pulse widths from tens to hundreds of nanoseconds range) were suggested by several researchers. Liu and Neiger ${ }^{9,10}$ and Laroussi et al. ${ }^{11}$ applied submicrosecond unipolar pulses with success to enhance energy-transfer efficiency to dielectric barrier discharges (DBD) at low pressure and high pressure, respectively. Liu and Neiger ${ }^{9}$ found that the energy efficiency for ozone synthesis is 30\% higher with pulsed DBD than that driven with sine-wave voltages. Mildren and Carman ${ }^{12}$ and Carman and Mildren ${ }^{13}$ found that the UV power output from a xenon excimer lamp driven by $\sim 150$-ns short pulses had an energy efficiency three times higher than the same lamp excited by sine-wave voltages.

One reason for the better energy transfer to the plasma is that two consecutive discharges occur for each applied voltage pulse. The first discharge occurs at the voltage pulse rising edge, followed by a second discharge at the falling edge of the voltage pulse. ${ }^{9-11}$ The second discharge ignites without energy input from the external circuit. The energy

\footnotetext{
a) Author to whom correspondence should be addressed; electronic mail: mlarouss@odu.edu
}

needed is provided by the accumulated surface charges left from the first discharge. These double discharges do not occur under normal low-frequency sine-wave excitation. This process ultimately leads to a much improved power transfer to the plasma.

In this paper, a specially designed pulsed DBD-based discharge was used to study the UV emission and active species generation efficiency with gas mixtures containing different percentages of $\mathrm{He}$ and $\mathrm{N}_{2}$. The operating pressure was $1 \mathrm{~atm}$, with residual trace amounts of air present in the discharge chamber. First, the gas temperature was measured by comparing the experimental $\mathrm{N}_{2}(C-B) 0-0$ transition spectrum with simulation results. This was followed by a detailed study of the UV emission power density from the discharge for different percentages of $\mathrm{He}$ and $\mathrm{N}_{2}$ and different pulse frequencies. In Sec. III C, to identify the excited species responsible for the UV emission and other chemically important species, emission spectroscopy was used. Because of the presence of oxygen (from residual traces of air), molecules such as $\mathrm{NO}$ and $\mathrm{NO}_{2}$ were formed. Therefore, a calibrated multigas detector was used to measure the absolute concentrations of $\mathrm{NO}$ and $\mathrm{NO}_{2}$ for different pulse frequencies.

\section{EXPERIMENTAL SETUP}

Figure 1 is a schematic of the discharge setup. It comprises two parallel electrodes separated by a gap. One of the electrodes is made of a $2 \times 2$ in $^{2}$ aluminum plate covered by an alumina $\left(\mathrm{Al}_{2} \mathrm{O}_{3}\right)$ sheet. The dimensions of the alumina sheet are $75 \times 75 \times 1 \mathrm{~mm}^{3}{ }^{3}$. The second electrode is made of a copper disk (diameter of $5.7 \mathrm{~cm}$ ) with several holes through which the operating gas is injected. The diameter of 


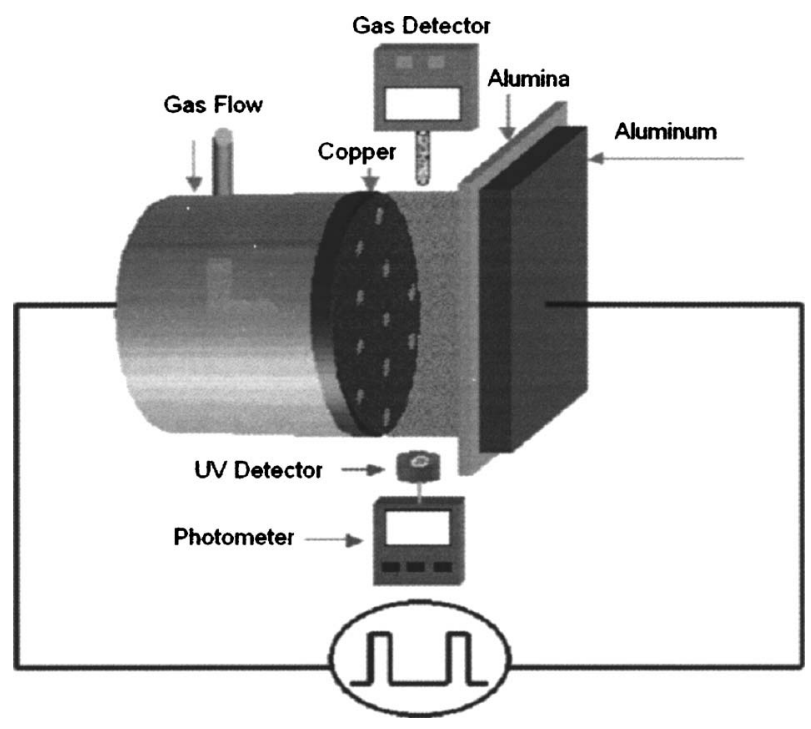

FIG. 1. Experimental setup of the discharge system with diagnostics.

the holes is about $1 \mathrm{~mm}$. The distance between nearby holes is $5 \mathrm{~mm}$. This copper electrode is not covered by a dielectric. The distance of the gap between the electrodes is adjustable from $1 \mathrm{~mm}$ to a few centimeters. The gas flows out of the holes and into the discharge gap. A multigas manifold with flow meters was used to adjust the percentage of $\mathrm{He}$ and $\mathrm{N}_{2}$. The plasma was driven by a pulse generator capable of producing narrow high-voltage pulses (pulse width at a few hundred nanoseconds) at adjustable repetition rates. Detailed description of the pulsed power supply can be found in Ref. 11 .

For the identification of excited species and the determination of gas temperature, optical emission spectroscopy (OES) was conducted with a half-meter spectrometer (Acton Research SpectraPro 500i). To carry out absolute measurements of the emitted UV power, a radiometer/photometer (International Light. Inc. model: IL1400A) (165-310 nm) was used. The distance from the UV detector to the axis of the copper disk was $6 \mathrm{~cm}$. To identify the excited species responsible for the UV emission and the other chemically important species present in the plasma, emission spectra in the 200-800-nm range were recorded. The absolute concentrations of $\mathrm{NO}$ and $\mathrm{NO}_{2}$ were measured by a multigas detector (RAE System: model PGM-7840). The gas detector was located $1 \mathrm{~cm}$ from the plasma surface.

\section{EXPERIMENTAL RESULTS AND OBSERVATIONS}

For all the experimental results presented in this paper the applied voltage, pulse width, pulse rise time, and the gap distance were $V_{a}=9 \mathrm{kV}, t_{\mathrm{PW}}=500 \mathrm{~ns}, \tau_{r}=50 \mathrm{~ns}$, and $d_{\text {gap }}$ $=2 \mathrm{~mm}$, respectively.

\section{A. Gas temperature measurement}

One of the most attractive features of nonequilibrium plasmas is that the gas temperature remains close to room temperature (or slightly above room temperature). Here, the gas temperature was determined by analyzing the rotational structure of the $\mathrm{N}_{2}$ second positive system emission. This rotational structure contains information on the rotational

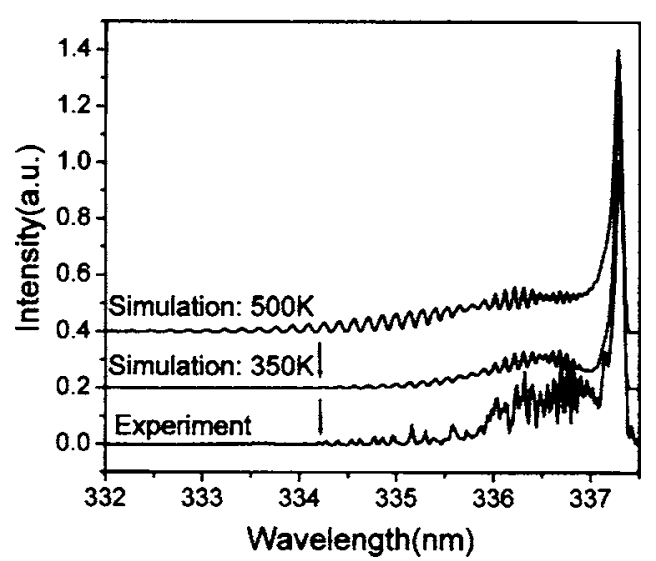

FIG. 2. Experimental and simulation spectra of $\mathrm{N}_{2}$ second positive $0-0$ transition. Applied voltage $=9 \mathrm{kV}$, pulse frequency $=1 \mathrm{kHz}$, pulse width $=500 \mathrm{~ns}$, gap distance $=2 \mathrm{~mm}$, and operating mixture gas: $\mathrm{He}(90 \%)$ $+\mathrm{N}_{2}(10 \%)$.

temperature. Because of the low energies needed for rotational excitation and the short transition times, molecules in the rotational states and the neutral gas molecules are in equilibrium. Therefore, the gas temperature can be directly inferred from the rotational temperature. ${ }^{14}$ To determine the gas temperature, we compared the experimentally measured spectra with the simulated spectra of the $0-0$ band of the second positive system of nitrogen at different temperatures. Figure 2 shows the experimental and simulated spectra results at different gas temperatures for a $\mathrm{He}(90 \%)$ $+\mathrm{N}_{2}(10 \%)$ operating gas mixture. The spectral resolution is $0.02 \mathrm{~nm}$ (grating: $3600 \mathrm{~g} / \mathrm{mm}$, slit width: $50 \mu \mathrm{m}$ ). The curves were intentionally shifted vertically for better separation. Note that the apparent inconsistency of the spectra between 336 and $337 \mathrm{~nm}$ is caused by the emission of NO in this band. According to Fig. 2, the higher the gas temperature, the further the band extends towards the short wavelengths. For a gas temperature of $350 \mathrm{~K}$, the simulation results show that the band stops at about $334.2 \mathrm{~nm}$ (as shown by the arrow); this is approximately the same as our experimental results. Therefore we concluded that the gas temperature was about $350 \mathrm{~K}$. When the percentages of He (100\%$70 \%)$ and $\mathrm{N}_{2}(0 \%-30 \%)$ were varied, it was found that the gas temperature did not change appreciably (stayed in the neighborhood of $350 \mathrm{~K}$ ). In addition, when the pulse frequency was increased from 1 to $10 \mathrm{kHz}$, the gas temperature only increased relatively slightly (less than $50 \mathrm{~K}$ ).

\section{B. UV power measurement}

UV emission was studied for various mixtures containing different percentages of $\mathrm{He}$ and $\mathrm{N}_{2}$. Figures $3(\mathrm{a})-3(\mathrm{c})$ show the integrated UV emission power densities for different percentages of $\mathrm{He}$ and $\mathrm{N}_{2}$ and for different pulse frequencies. Figure 3(a) shows that when only helium is used $\left[\mathrm{He}(100 \%)+\mathrm{N}_{2}(0 \%)\right]$ as the operating gas, the emitted UV power density, $P_{\mathrm{UV}}$, increased linearly with the pulse frequency, reaching about $0.18 \mathrm{~mW} / \mathrm{cm}^{2}$ at $10 \mathrm{kHz}$. When nitrogen $\left[\mathrm{He}(0 \%)+\mathrm{N}_{2}(100 \%)\right]$ is used as the operating gas, 


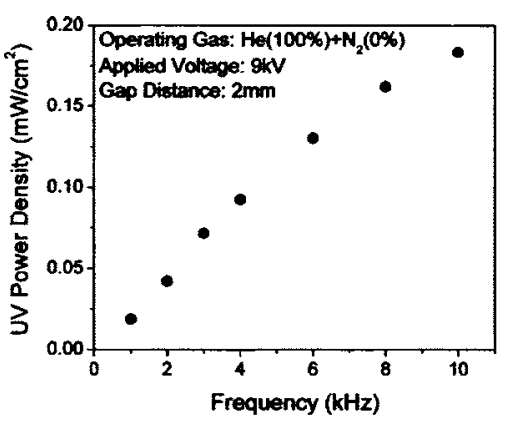

(a)

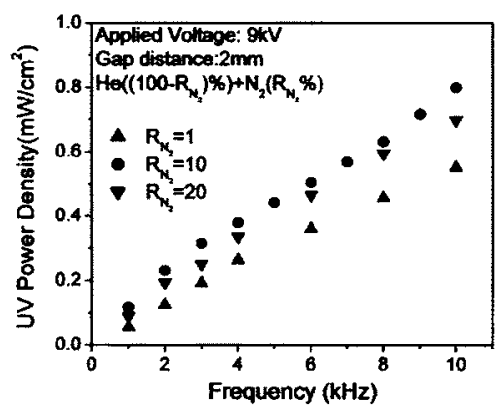

(c)

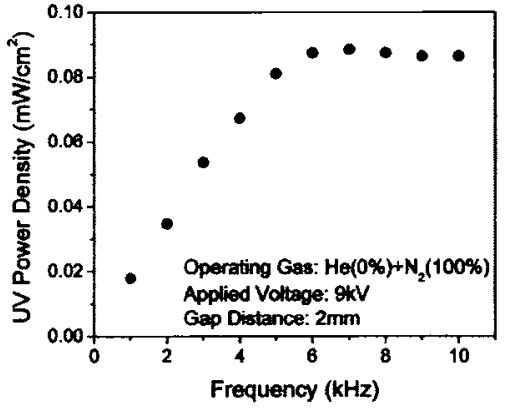

(b)

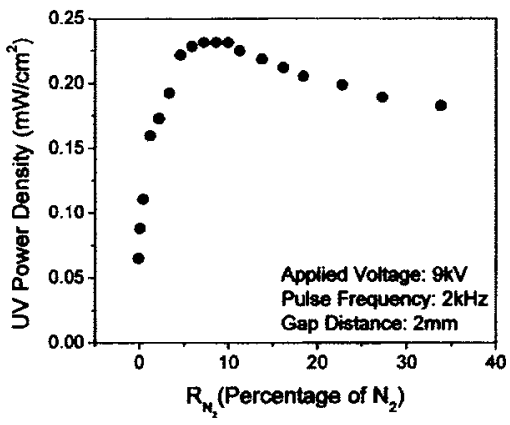

(d)
FIG. 3. Integrated UV emission power density vs pulse frequencies for (a) $\mathrm{He}(100 \%)+\mathrm{N}_{2}(0 \%)$ plasma and (b) $\mathrm{He}(0 \%)+\mathrm{N}_{2}(100 \%)$ plasma, (c) integrated UV emission power densities for three different percentages $(1 \%, 10 \%$, and $20 \%)$ of $\mathrm{N}_{2}$ in a $\mathrm{N}_{2} / \mathrm{He}$ mixture vs pulse frequency, and (d) UV emission power density vs the percentage of $\mathrm{N}_{2}$ at a fixed pulse frequency of $2 \mathrm{kHz}$. ( $R_{\mathrm{N}_{2}}$ : percentage of $\mathrm{N}_{2}$ )
Fig. 3(b) shows that, in the low-frequency range, $P_{\mathrm{UV}}$ initially increased with the pulse frequency, but around $6 \mathrm{kHz}$, $P_{\mathrm{UV}}$ reached a saturation value of about $90 \mu \mathrm{W} / \mathrm{cm}^{2}$.

To improve the UV emission power density, helium mixed with different percentages of $\mathrm{N}_{2}$ was then used. Figure 3(c) shows that, for three different percentages of $\mathrm{N}_{2}$ in a $\mathrm{He}$ balance, $P_{\mathrm{UV}}$ increases linearly with pulse frequency, and is much higher than that shown in Figs. 3(a) and 3(b). According to Fig. 3(c), $P_{\mathrm{UV}}$ is highest when $10 \%$ of nitrogen $\left[\mathrm{He}(90 \%)+\mathrm{N}_{2}(10 \%)\right]$ was used. In this case, $P_{\mathrm{UV}}$ is more than four times higher than that of the $\mathrm{He}(100 \%)$ case. To further investigate how the percentage of $\mathrm{N}_{2}\left(R_{\mathrm{N}_{2}}\right)$ affects $P_{\mathrm{UV}}$, we measured $P_{\mathrm{UV}}$ with $\mathrm{He}\left[\left(100-R_{\mathrm{N}_{2}}\right) \%\right]+\mathrm{N}_{2}\left(R_{\mathrm{N}_{2}} \%\right)$ as operating gas mixtures at a fixed pulse frequency of $2 \mathrm{kHz}$. Figure 3(d) shows that, when the percentage of $\mathrm{N}_{2}$ was increased from $0 \%$ to $5 \%, P_{\mathrm{UV}}$ increased from about 0.07 to $0.23 \mathrm{~mW} / \mathrm{cm}^{2}$. Increasing the percentage of $\mathrm{N}_{2}$ up to about $10 \%$ did not greatly affect the value of $P_{\mathrm{UV}}$. However, further increase of $\mathrm{N}_{2}$ beyond $10 \%$ led to a decline in $P_{\mathrm{UV}}$.

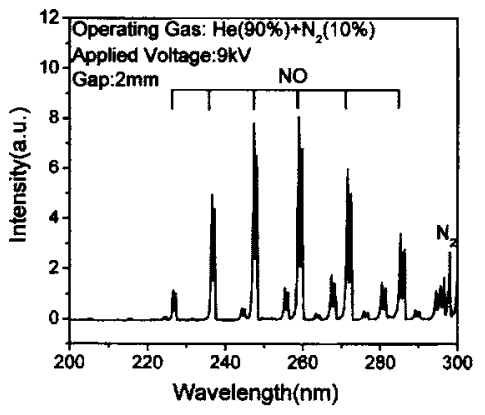

(a)

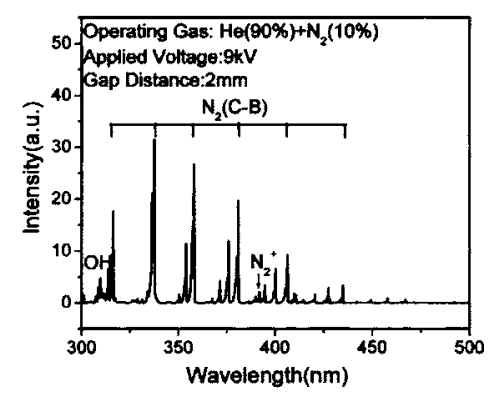

(b)

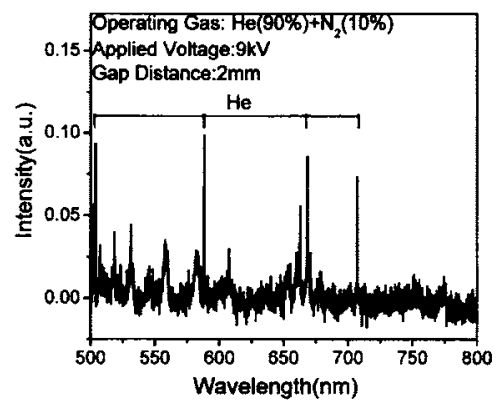

FIG. 4. Emission spectra from (a) 200 to $300 \mathrm{~nm}$, (b) 300 to $500 \mathrm{~nm}$, and (c) 500 to $800 \mathrm{~nm}$ for the $\mathrm{He}(90 \%)+\mathrm{N}_{2}(10 \%)$ plasma. Trace amounts of oxygen are present from residual air. 


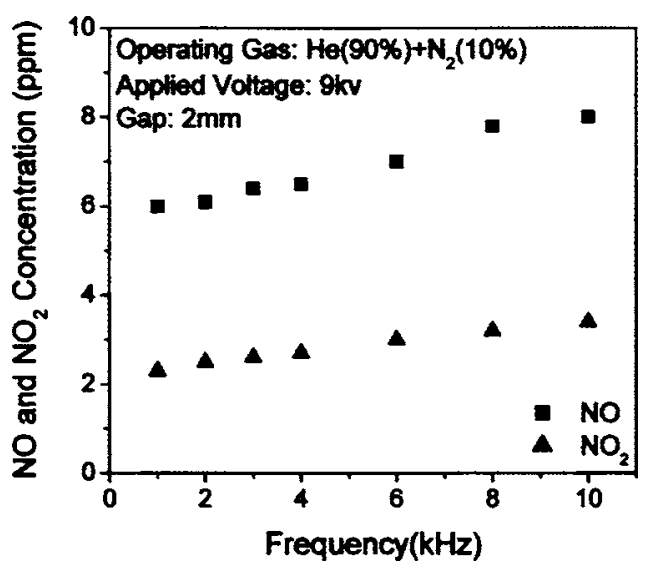

FIG. 5. $\mathrm{NO}$ and $\mathrm{NO}_{2}$ concentrations vs pulse frequency for the $\mathrm{He}(90 \%)$ $+\mathrm{N}_{2}(10 \%)$ plasma. Oxygen presence is due to trace amounts of residual air

\section{Emission spectra}

As shown above, UV emission depends greatly on the gas mixture used in the plasma. To better understand the UV emission characteristics and to identify the presence of chemically reactive excited species in the plasma, emission spectroscopy was used to measure the emission spectra in the 200-800-nm wavelength range (no emission was observed in the 165-200-nm range), under different gas operating conditions. For all of the recorded emission spectra, the pulse repetition rate $f$ was $1 \mathrm{kHz}$ and the operational parameters of the spectrometer were unchanged (grating: $1200 \mathrm{~g} / \mathrm{mm}$, slit width: $100 \mu \mathrm{m})$.

Figure 4(a), which shows the emission spectra from 200 to $300 \mathrm{~nm}$ for a $\mathrm{He}(90 \%)+\mathrm{N}_{2}(10 \%)$ mixture, clearly indicates that excited $\mathrm{NO}$ radicals are the main source of the UV emission. The $\mathrm{N}_{2}(C-B)$ emission band also contributes to the UV output. Varying the percentages of $\mathrm{He}$ and $\mathrm{N}_{2}$ we observed similar emission spectra but with weaker intensities. Spectra in the wavelength range of 300-800 nm [see Figs. 4(b) and 4(c)] reveal the presence of excited $\mathrm{OH}, \mathrm{N}_{2}$, $\mathrm{N}_{2}^{+}$, and $\mathrm{He}$ in the plasma.

\section{D. $\mathrm{NO}$ and $\mathrm{NO}_{2}$ concentrations}

Since most of the emission in the UV range was found to originate from $\mathrm{NO}$ and since $\mathrm{NO}$ is easily oxidized to $\mathrm{NO}_{2}$ by reaction with $\mathrm{O}_{2}, \mathrm{O}_{3}$, etc., ${ }^{15,16}$ we proceeded to measure the absolute concentrations of $\mathrm{NO}$ and $\mathrm{NO}_{2}$. A multigas detector was used for this task. Figure 5 shows the $\mathrm{NO}$ and $\mathrm{NO}_{2}$ concentrations for a $\mathrm{He}(90 \%)+\mathrm{N}_{2}(10 \%)$ mixture. It shows that both $\mathrm{NO}$ and $\mathrm{NO}_{2}$ concentrations have approximately linear relationships with pulse frequency. The maximum measured $\mathrm{NO}$ and $\mathrm{NO}_{2}$ concentrations were about 8 and 4 ppm, respectively.

\section{DISCUSSION}

As stated above, the UV emission from a $\mathrm{He}(90 \%)$ $+\mathrm{N}_{2}(10 \%)$ plasma is much higher than that when helium or nitrogen alone were used as operating gases. Nitrogen oxide (NO) dominated this emission (where the residual traces of air provided the oxygen to form NO). This improved UV emission can be explained as follows. In order to enhance

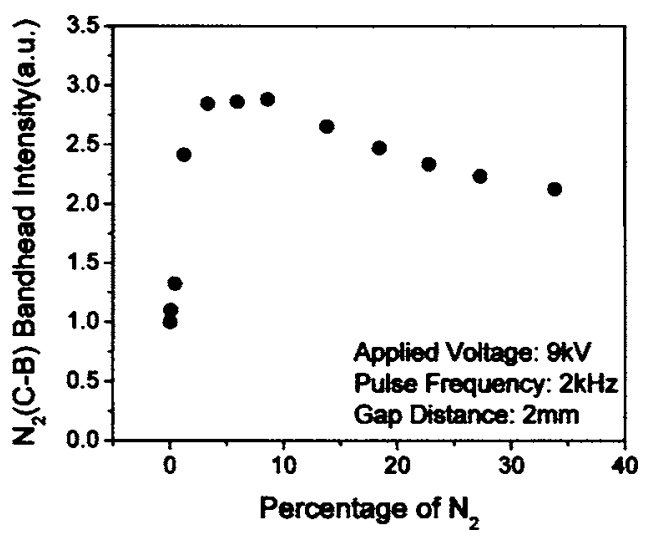

FIG. 6. $\mathrm{N}_{2}(C-B)$ 0-0 transition bandhead $(337 \mathrm{~nm})$ intensity vs the percentage of $\mathrm{N}_{2}$ in a He/ $\mathrm{N}_{2}$ mixture at a fixed pulse frequency of $2 \mathrm{kHz}$.

UV emission, NO had to be excited to the $\mathrm{NO}\left(A^{2} \Sigma^{+}\right)$state (excitation energy $E_{\mathrm{NO}^{*}}=5.5 \mathrm{eV}$ ). This can occur via collisions with helium metastables, $\mathrm{He}^{*}$, or with $\mathrm{N}_{2}\left(C^{3} \Pi_{u}\right)$ (excitation energy $\left.E_{\mathrm{N}_{2}^{*} \mathrm{C}}=11.1 \mathrm{eV}\right)$. According to the spectra that we measured, the $\mathrm{N}_{2}(C-B)$ emission intensity from the plasma with a $\mathrm{He}(90 \%)+\mathrm{N}_{2}(10 \%)$ mixture was several times higher than that of helium-only or nitrogen-only plasmas. Because the mass of $\mathrm{N}_{2}$ is seven times higher than that of $\mathrm{He}$, the NO excitation cross section by $\mathrm{N}_{2}\left(C^{3} \Pi_{u}\right)$ is likely to be higher than that by $\mathrm{He}^{*}$. Therefore, the plasma with the higher $\mathrm{N}_{2}\left(C^{3} \Pi_{u}\right)$ concentration will excite more NO, and as a result emits more UV. To confirm this assumption, we also measured the $\mathrm{N}_{2}(C-B)(0-0)$ transition bandhead intensity $(337 \mathrm{~nm})$ for different percentages of $\mathrm{N}_{2}$ and He mixtures. Figure 6 shows that the emission intensity of this bandhead has a very similar behavior as that of the emitted UV power density shown in Fig. 3(d).

Since most of the UV emission came for the excited NO molecule, the presence of trace amounts of oxygen is therefore required. However, if too much oxygen is added to the gas mixture, the UV emission drops drastically. Figure 7 shows that when just $1 \%$ of oxygen was added to a $\mathrm{He}(89 \%)+\mathrm{N}_{2}(10 \%)$ mixture, the intensity of the NO emission lines between 200 and $300 \mathrm{~nm}$ became very weak. Two reasons contribute to this result: (1) In the presence of oxygen $\mathrm{NO}$ is quickly oxidized to $\mathrm{NO}_{2}$. Measurements of the absolute concentration of $\mathrm{NO}_{2}$ showed a two-order-of-

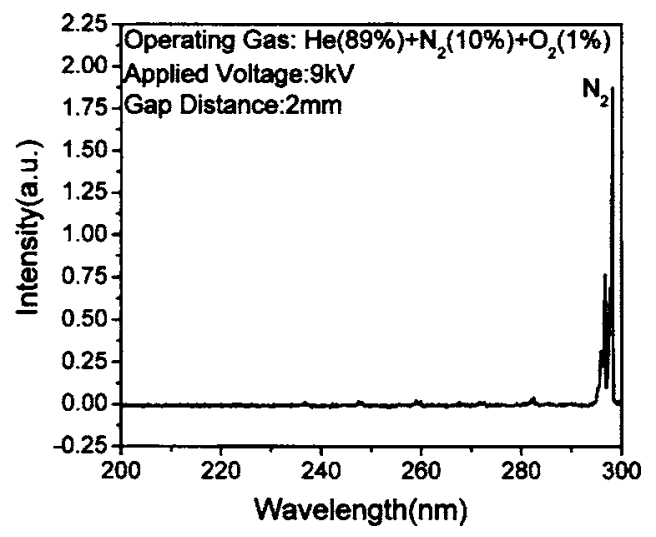

FIG. 7. Emission spectra from a $\mathrm{He}(89 \%)+\mathrm{N}_{2}(10 \%)+\mathrm{O}_{2}(1 \%)$ plasma. 
magnitude increase (up to $500 \mathrm{ppm}$ of $\mathrm{NO}_{2}$ ) when $1 \%$ of oxygen was added. (2) Since oxygen has a large electron attachment cross section, it affects the electron energy distribution function in a way that results in less excited species and consequently less UV emission.

Another important observation was that the UV emission power density from a nitrogen plasma was weaker than that from a helium plasma (both in the presence of trace amounts of air). This is because without the presence of He metastables, the only pathway to excite the ground state of $\mathrm{N}_{2}$ to $\mathrm{N}_{2}(C)$ state is via electron impact. ${ }^{17,18}$ The cross section of this process is smaller than that via $\mathrm{He}^{*}$. So the concentration of $\mathrm{N}_{2}(C)$ state is lower and as a result less $\mathrm{NO}$ is excited and less UV is emitted from the nitrogen plasma.

\section{CONCLUSION}

A specially designed pulsed dielectric barrier discharge was used to generate a diffuse atmospheric pressure plasma. The gas temperature of the plasma was measured to be close to $350 \mathrm{~K}$. The UV emission power density, $P_{\mathrm{UV}}$, measurements show that proper mixture of $\mathrm{He}$ and $\mathrm{N}_{2}$ improves the UV emission dramatically. With $5 \%$ to $10 \%$ of $\mathrm{N}_{2}$ mixed with $\mathrm{He}, P_{\mathrm{UV}}$ reached about $0.8 \mathrm{~mW} / \mathrm{cm}^{2}$ (for $f=10 \mathrm{kHz}$ ), and was more than four to nine times higher than that for $\mathrm{He}$ or $\mathrm{N}_{2}$ plasmas, respectively. The emission spectra show that most of the UV was emitted by excited $\mathrm{NO}$ and $\mathrm{N}_{2}$. The emission spectra from a $\mathrm{He}(90 \%)+\mathrm{N}_{2}(10 \%)$ plasma show relatively high concentrations of excited $\mathrm{NO}$ and $\mathrm{N}_{2}$. In addition to $\mathrm{NO}, \mathrm{NO}_{2}$, and excited $\mathrm{OH}, \mathrm{N}_{2}^{+}$was detected.

\section{ACKNOWLEDGMENT}

This work was supported by the U.S. Air Force Office of Scientific Research (AFOSR).

${ }^{1}$ R. Dorai and M. J. Kushner, J. Phys. D 36, 666 (2003).

${ }^{2}$ M. Laroussi, IEEE Trans. Plasma Sci. 24, 1188 (1996).

${ }^{3}$ S. Kuo and D. Bivolaru, Phys. Plasmas 8, 3258 (2001).

${ }^{4}$ A. Fridman, A. Chirokov, and A. Gutsol, J. Phys. D 38, R1 (2005).

${ }^{5}$ G. Nersisyan and W. G. Graham, Plasma Sources Sci. Technol. 13, 582 (2004).

${ }^{6}$ U. Kogelschatz, Plasma Phys. Controlled Fusion 46, B63 (2004).

${ }^{7}$ J. L. Lauer et al., J. Appl. Phys. 96, 4539 (2004).

${ }^{8}$ M. Laroussi and F. Leipold, Int. J. Mass. Spectrom. 233, 81 (2004).

${ }^{9}$ S. Liu and M. Neiger, J. Phys. D 34, 1632 (2001).

${ }^{10}$ S. Liu and M. Neiger, J. Phys. D 36, 3144 (2003).

${ }^{11}$ M. Laroussi, X. Lu, V. Kolobov, and R. Arslanbekov, J. Appl. Phys. 96, 3028 (2004).

${ }^{12}$ R. P. Mildren and R. J. Carman, J. Phys. D 34, L1 (2001).

${ }^{13}$ R. J. Carman and R. P. Mildren, J. Phys. D 36, 19 (2003).

${ }^{14}$ G. Faure and S. M. Shkol'nik, J. Phys. D 31, 1212 (1998)

${ }^{15}$ I. A. Kossyi, A. Yu. Kostinsky, A. A. Matveyev, and V. P. Silakov, Plasma Sources Sci. Technol. 1, 207 (1992).

${ }^{16}$ J. T. Herron, J. Phys. Chem. Ref. Data 28, 1453 (1999).

${ }^{17}$ W. Zhang, T. S. Fisher, and S. V. Garimella, J. Appl. Phys. 96, 6066 (2004).

${ }^{18}$ C. D. Pintassilgo, J. Loureiro, and V. Guerra, J. Phys. D 38, 417 (2005). 